\title{
High Performance Management Practices and Sustainability of SMEs. Evidence from Manufacturing and Services-based Industries in Pakistan
}

\author{
Abdul Raziq * $\quad$ Retha Wiesner ${ }^{\dagger}$
}

\begin{abstract}
Prior research on high performance management practices (HPMP) has primarily examined the relationship between HPMP and firm performance in the context of large organisations. However, this study examines the relationship between HPMP and Sustainability outcomes (firm performance) in small and medium-size enterprises (SMEs) and also within a specific cultural background which is under researched. This research study is related to both theory and practice. The main relevance lies in analyzing the relationship between HPMP and sustainability outcomes in SMEs. This research study relates to theory by applying the resource-based view and configurational approaches used in this study. The study employed a quantitative methodology. Data were collected through a self-administered survey questionnaire. The questionnaire was adopted from a previous validated survey measuring HPMP in Australian SMEs. The target population consisted of SMEs operating in the city of Karachi, Pakistan. Stratified random sampling was applied to collect data from two stratums i.e. manufacturing and service-sector SMEs. A total of 703 firms were selected, contacted by phone, and invited to participate in this survey. Of these firms, 357 SMEs (50.78 percent response rate) accepted the invitation to fill out the survey questionnaire. Most of the respondents who agreed requested that the researcher to visit their organizations personally. The data were analyzed by using Structural Equation Modeling techniques including exploratory factor analysis. The findings indicate a positive significant relationship between HPMP and sustainability outcomes. The link between these HPMP and the sustainability of SMEs demonstrates the value and importance of HPMP in achieving sustainability.
\end{abstract}

Keywords: High performance management practices, small and medium-size enterprises, structural equation modeling, sustainability outcomes.

\section{Introduction}

Prior research has mainly focused on the relationship between 'individual' human resource (HR) practices and firm performance, however, current research studies are based on 'bundles', 'systems' or 'configurations' of HR practices and their impact upon performance outcomes (De Kok, Den Hartog, et al., 2006; Drummond \& Stone, 2007). These configurations of HR practices have been shown to lead to better firm performance (Delery \&

\footnotetext{
*Associate Professor, Faculty of Management Sciences, Balochistan University of Information Technology, Engineering \& Management Sciences. Quetta, 87300, Pakistan. E-mail: raziq@buitms.edu.pk

${ }^{\dagger}$ Professor, School of Management and Enterprise, University of Southern Queensland, Australia.
} 
Doty, 1996; Huselid, 1995; Wright, Gardner, Moynihan, \& Allen, 2005) Such bundles of HR practices are called high performance management practices (HPMP) in the current study. The current literature has used the term in many different ways, such as high involvement (Bryson, Forth, \& Kirby, 2005; Gollan, 2005; Guthrie, Spell, \& Nyamori, 2002), high commitment (Whitener, 2001), high performance work systems (Beltrán-Martín, Roca-Puig, Escrig-Tena, \& Bou-Llusar, 2008; Datta, Guthrie, \& Wright, 2005; Murphy, DiPietro, \& Murrmann, 2007; Drummond \& Stone, 2007; Takeuchi, 2009; Tsai, 2006; Way, 2002), high performance work practices (Huselid, 1995; Zhang \& Li, 2009; Bae, Chuma, Kato, Kim, \& Ohashi, 2011), high performance human resource practices (Kehoe \& Wright, 2013) and high performance management practices (Wiesner \& McDonald, 2001). While several terms are used interchangeably, they all refer to the same philosophy (Evans \& Davis, 2005; Pfeffer, 1998; Wiesner \& McDonald, 2001).

The relationship between HPMP and sustainability outcomes(firm performance) has been shown by recent literature. However, much of the research studies focused primarily on large organisations. For instance, in the US, in a study of Fortune 1000 large companies, Lawler, Mohrman, and Ledford (1995) analysed employee involvement and TQM. Their model was intended to improve employees' skills and knowledge, hence having an impact on motivation of employees. Huselid (1995) studied the relationship among HPMP and turn-over, productivity and firm financial performance. He used 13 high performance management practices related to personnel selection, performance appraisal, incentive compensation, job design, grievance procedures, information sharing, attitude assessment and labour management participation. In the United Kingdom, Wood and De Menezes (1998) performed an analysis of HPMP, including different facets of quality management, for example team work and quality circles. Moreover, Kehoe and Wright (2013) found positive relationship between high performance HR practices and employees attitude and behaviour.

The objective of this study is to examine the relationship between HPMP and sustainability outcomes (financial sustainability outcome and market-based sustainability outcome) in the context of small and medium-size enterprises (SMEs) in Pakistan. Our interest in undertaking this research is justified on the basis of two main aspects. Firstly, SMEs comprise the largest and constantly growing proportion of the Pakistani economy, and the majority of these firms manufacture products and provide services to national and international markets (Hussain et al., 2015). Moreover, Pakistani SMEs are playing significant role in GDP growth, and employment generation (Afraz, Hussain, \& Khan, 2014; Irfan, Kee, Qureshi, \& Hussain, 2014). Despite this, there is still a dearth of systematic research available about the utilisation of HPMP in these organisations and the practices that contribute to their long-term sustainability. Secondly, Pakistan has a unique culture (Hofstede, 2010; Khilji, 2004) and SMEs face quite unique challenges (Afraz et al., 2014) compared to other countries, which makes a study focusing on HPMP a worthwhile endeavour. The cultural dimensions have implications for how employees are managed in SMEs. Pakistanis tend to have a desire for security, independence in decision-making and seeking more authority. The society has two main classes, elite and non-elite (the general public). The elite class is represented by money, power and status. However, the non-eliteclass desires basic rights of justice and democracy (Khilji, 2004). These status differences are also reflected in Pakistani organisations which are in general authoritarian in nature, 
with top management making the major decisions. There tends to be minimum employee involvement in decision making and limited communication with staff (Khilji, 2004). In addition, the majority of Pakistani organisations are bureaucratic and centralised, with little delegated authority to lower level employees (p. 143). The results from similar studies (De Kok \& Uhlaner, 2001; Delery \& Doty, 1996; Marlo, 2000; Rowden, 2002; Zheng, O'Neill, \& Morrison, 2009) conducted in different countries (mostly related to developed economies and with different cultural contexts than those of Pakistan) are showing mixed results regarding the adoption of HPMP and their relationship with sustainability outcomes. Consequently, owing to the cultural differences, these results cannot necessarily be applied in the Pakistani context. Moreover, researchers also suggest that similar research studies should be conducted in developing countries to take into consideration different cultural backgrounds (Heneman, Tansky, \& Camp, 2000; Shih, Chiang, \& Hsu, 2006).

\section{Literature Review}

This study draws on two theoretical perspectives including the resourced-based view, and the configurational perspective. These theoretical perspectives are discussed and an explanation is provided as to why these perspectives are relevant to the study.

\section{The Resource-based View}

A resource is defined as 'anything which could be thought of as a strength or weakness of a given firm' (Wernerfelt, 1984). Resources are classified into tangible and intangible assets. For example: machinery, brand names, trademarks, efficient procedures, capital and skilled employees (Wernerfelt, 1984). Barney $(1991,1995)$ further classified these resources into three broad categories: physical capital resources, human capital resources and organisational capital resources. Physical capital resources of a firm include for example, raw materials, plant and equipment, technology and geographical location. Human capital resources include for example, training, experience, judgement and intelligence of individual employees in a firm. Organisational capital resources include for example, a firm's formal and informal planning, controlling and coordinating systems and informal relationships among employees within a firm and with other firms in its surrounding.

According to the resource-based view, the firm's resources are the basis of competitive advantage (Wright, McMahan, \& McWilliams, 1994). Barney (1991) defined competitive advantage as, when a firm is implementing a value creating strategy not simultaneously being implemented by any current or potential competitors'. Based on the resource-based view, a firm can achieve competitive advantage, only if its resources are heterogeneous and immobile. Such resources are different for different firms and cannot be obtained from the resource market by the competing firms (Wright et al., 1994).

Furthermore, based on the resource-based view, the firm's resources may become a source of sustained competitive advantage. Barney (1991) described the firm's sustained competitive advantage as 'when it is implementing a value creating strategy not simultaneously being implemented by any current or potential competitors and when these other 
firms are unable to duplicate the benefits of this strategy'. As a result, for sustained competitive advantage, a firm's resources must meet four criteria (a) it must provide value to the firm, (b) it must be unique among a firm's current and potential competitors , (c) the resources must not be imitable and (d) the resources must not be substituted by other competing firms (Barney, 1991, 1995).

The resource-based view therefore proposes that a firm's human resources are an important component of sustained competitive advantage (Barney, 1991; Wernerfelt, 1984). (Wright et al., 1994) defined human resources as 'the pool of human capital under the firm's control in a direct employment relationship'. According to Schuler and MacMillan (1984) human resources (if managed effectively) can be a source of competitive advantages in the form of increased profitability, low employee turnover, high product quality and low production cost advantage. Moreover, Ferligoj, Prašnikar, and Jordan (1997) concluded that good relationships among employees, their skills and innovativeness can lead to a competitive advantage for the firm. In addition, their study indicated that higher level of staffing and benefits to employees will result in higher level of competitive advantage . However, according to (Wright et al., 1994) sustained competitive advantage comes from the human resources themselves, not the practices to manage them.

According to Koch and McGrath (1996) investments in the expansion of a distinctive human resource lead to enhanced productivity. Additionally, an increase in the skills and knowledge base of employees provide the firm a power of inimitability in a way that competitors cannot easily replicate. Similarly, Wright et al. (1994) assert that a firm with a highly skilled and motivated work force has greater probability to achieve sustainable competitive advantage.

Furthermore, Wright, Dunford, and Snell (2001) argue that HPMP relate to competitive advantage in several ways. Firstly, it helps in creating a culture that facilitates the continuation of sole competencies. Secondly, HPMP may support and sustain socially composite relationships illustrated by trust, knowledge sharing and team work. Finally, HPMP tend to develop a high quality human team that is difficult and costly for competitors to imitate.

Although it is recognised that sustained competitive advantage comes from the human resources themselves, not the practices to manage them, the relevance of the resource based theory within the context of this study lays specifically in the notion that human resources (if managed effectively through HPMP) can be a source of competitive advantage in the form of increased financial performance, market performance and human resource performance. An examination of the way in which Pakistani SMEs employ specific HPMP and how these practices impact upon various performance outcomes is central to this study.

\section{Configurational Perspective}

The configurational perspective is based on internally consistent configurations of HR practices, or employment systems that maximise horizontal fit and identify the relationship between HR practices and strategic configurations to maximise vertical fit (Arthur, 1994; Delery \& Doty, 1996; Fernando, Pedro, \& Gonzalo, 2005; Huselid \& Becker, 1996; Ichniowski, Shaw, \& Prennushi, 1997). Delery and Doty (1996) has proposed two types of 
employment systems: the market-type system and the internal system. They defined the market type system as hiring employees from the outside labour market, providing little training, and evaluate their performance through output measures. Employees are rewarded based on their performance. They do not have employment security and are not consulted in organisation decision making process.

On the other hand, the internal system is described as recruiting employees from within an organisation. Employees have the opportunity for extensive socialisation and training. Their performance is evaluated through an appraisal feedback system. Employees are considered as an important source of information and are consulted in the vital issues of organisation. Their jobs are secure and narrowly defined (Delery \& Doty, 1996).

Moreover, the configurational perspective is supported by the strategic configurations developed by the Miles, Snow, Meyer, and Coleman (1978) typology. Miles et al. (1978) assessed the strategy types of defenders (firms that rarely innovate), analysers (firms that are moderately innovative) and prospectors (firms that are highly innovative) with regard to different types of HR practices needed. They further assume that HR practices vary among strategy types as a result of the different behaviours and skills necessary to carry out the strategy.

According to Delery and Doty (1996) the firms pursuing these strategies (defender, prospector and analyser) should implement different types of employment systems. They further argue that as defenders concentrate on producing low cost products and services, effective HR practices should direct long term commitment to an organisation. The firm should select employees with product specific skills and knowledge. Moreover, these skills can be enhanced through formal training and appraisal system. These HR practices direct the firm to create an environment of long-term commitment to the organisation and reduce the cost of replacing knowledge based employees.

On the other hand, prospectors are innovative firms and always search for new products and markets. These firms have less knowledge of the specific behaviours of employees that are required to perform these tasks. As a result, these firms always look outside to acquire the skills and knowledge-base of employees to produce the desired output. Thus, these firms should emphasise result oriented appraisal systems rather than a long term employment system (Delery \& Doty, 1996).

Analysers stand in the midpoint between defenders and prospectors. These types of firms operate in both stable market conditions like defenders, and changing market conditions like prospectors. These firms do not initiate change like prospectors. However, they follow the change more rapidly than defenders do (Delery \& Doty, 1996). As a result, specific HR practices consistent with the firm?s internal system are appropriate for a defender strategy. These practices include: internal career opportunities, formal training, behavioural-based appraisal, hierarchy-based compensation, job security, employee consultation and tightly defined jobs. On the other hand, the prospector strategy consistent with the market system requires HR practices, which entail: few internal career opportunities, lack of formal training, output-based appraisal, profit sharing, job insecurity, little employee consultation and broadly defined jobs (Delery \& Doty, 1996).

The configurational perspective hypothesise that adopting an ideal employment system (market system and internal system), with specific HR practices and an appropriate 
strategy will enhance firm performance (Baird \& Meshoulam, 1988; Delery \& Doty, 1996; Wright \& McMahan, 1992) However, this perspective assumes that the relationship between the HR practices (configurational patterns) and organisational performance is not linear as these practices are interdependent and their combined effect can be multiplied or divided. Thus, the configurational approach analyses the HR system as a complex and interactive system (Fernando et al., 2005).

Furthermore, the configurational approach has been supported by previous research studies (Chow, Huang, \& Liu, 2008; Gould-Williams, 2003; Shih et al., 2006). For instance, the findings of Shih et al. (2006) and Gould-Williams (2003) support the configurational perspective in a way that HPMP (employment security, selective hiring, team working, performance-related pay, training programs, participative work settings and incentive arrangements) work together to enhance organisational performance. In addition, the study by Chow et al. (2008) partially supports the notion that integrating HR configurations with business strategy enhances firm performance.

Although this study does not examine the strategy component within the configurational approach as discussed above, the configurational approach is relevant because the study explores how certain HPMP work together to enhance sustainability outcomes. This study examines the relationship between HPMP and sustainability outcomes in two ways: direct link (i.e. resource based view) and an indirect link (i.e. configurational perspective approach) between HPMP and performance outcomes. The resource based view approach is well accepted in the literature and widely used in high performance management research (Becker, Huselid, Becker, \& Huselid, 1998; Combs, Liu, Hall, \& Ketchen, 2006; De Kok \& Uhlaner, 2001; De Kok et al., 2006; Huselid, 1995; Shih et al., 2006; Tsai, 2006). The link between HPMP and sustainability outcomes (financial performance and market performance outcomes) is examined in this study. Nevertheless, there is very little evidence of the configurational perspective in research focusing on developing countries such as Pakistan (Yasmin, 2008).

\section{HPMP and Sustainability Outcomes in SMEs}

There is very limited application of HPMP which has been found in small firms (Kroon, Van De Voorde, \& Timmers, 2013). However, a substantial number of empirical studies conducted in large organisations have examined the effect of HPMP on sustainability outcomes (Datta et al., 2005; Ekwoaba, Ikeije, \& Ufoma, 2015; Huselid, 1995; Katou \& Budhwar, 2007; Kehoe \& Wright, 2013; Richard \& Johnson, 2001; Rose, Kumar, \& Yen, 2006; Wright et al., 2005; Zhang \& Li, 2009; Zheng et al., 2009). For instance, Huselid (1995) found that bundles of HR practices are associated with lower turnover and higher productivity and financial performance. Richard and Johnson (2001)found a relationship between effective HR systems and a decrease in employee turnover. Ekwoaba et al. (2015) argue that effective recruitment and selection criteria may effect organizational performance. Similarly, Guest, Michie, Conway, and Sheehan (2003) noted positive relationships between HR practices and lower turnover and higher profitability. Moreover, Kehoe and Wright (2013) also found positive relationship between high performance HR practices and employees attitude and behaviour. 
However, the link between HPMP and sustainability outcomes has been strongly criticised by Fleetwood and Hesketh (2006). They argue that HPMP-sustainability outcomes link is under theorized with lack of explanatory power. They further argue that more empirical cannot provide the solution for this problem. They pointed out that root cause of this problem is grounded in the level of philosophy of science particularly ontology, epistemology, methodology and causality. They further note that since the HPMP-sustainability outcomes link lack philosophical discussion, the under theorization and explanatory power issues are not yet addressed.

In view of the literature, the following hypotheses have been formulated

$H_{1}$ There is a significant positive relationship between HPMP (recruitment, selection, training and development, compensation, performance appraisal and consultation) and financial sustainability outcomes of SMEs.

$\mathrm{H}_{2}$ There is a significant positive relationship between HPMP (recruitment, selection, training and development, compensation, performance appraisal and consultation) and market based sustainability outcomes of SMEs.

\section{Methodology}

\section{Sample}

The relationship between HPMP and sustainability outcomes in Pakistani SMEs was studied by conducting a questionnaire survey in the industrial city of Karachi, Pakistan. The sampling frame was based on the data bases such as Korangi Association of Trade and Commerce (KATI) Karachi; Karachi Chamber of Commerce and Industry (KCCI) and Jamal's Yellow pages, Pakistan. However, the three databases were not specifically designed for SMEs. Nevertheless, these data bases were deemed to be the most reliable and updated databases in Karachi, Pakistan. A random sample of 703 firms was selected. The population was stratified by industry sectors such as manufacturing and services. These two sectors were selected based on their economic importance (Economic Survey, 2015) and their likelihood to have some management structure.

\section{Data Collection}

It was not possible to collect data in the 'normal' postal survey method and we had to utilise a team of 10 individuals to collect data from the selected sample owing to the following reasons: (1) security was an issue, (2) data collection commenced shortly after a major flood occurred in Pakistan, (3) SME managers who represented the target sample may not have a good command of the written English language, and (4) education levels of SME managers are low. The data collection team consisted of postgraduate research students at University of Karachi. A 2-day training course was conducted for the data collection team on the content of the survey itself and collection of the data through filling out the questionnaires by face-to-face collaboration with survey respondents. The research team 
was continuously monitored. The selected organisations were first asked about the size of their workforce and the number of employees they employ since the databases were not designed specifically for SMEs (as mentioned above). If the selected organisation fulfilled the requirements of the definition of a SME (20-250 employees), the SME manager was invited to participate in this survey. In cases where a particular organisation declined the invitation, it was replaced by contacting another organisation in the same industry as per the sampling frame.

A total of 703 firms were selected, contacted by phone and invited to participate in this survey. Of these firms, 357 SMEs (50.78 percent response rate) accepted the invitation to fill out the survey questionnaire. Most of the respondents who agreed requested that the research team to visit their organisations personally, and only a few respondents (from services sector) agreed to fill questionnaire by email (five firms). In each case, the procedure was explained to the respondents about how to fill the questionnaire out and they were assured that their responses would be treated as strictly confidential. The questionnaires were filled out by either the owner or human resource manager in each firm. In the end, 357 questionnaires were collected. Of the 357 responses collected from SMEs, 243 were from the manufacturing sector and 114 responses from the service sector. A total of 227 responses were collected from small firms (145 from manufacturing and 82 from service sector) and 130 responses from medium sized firms (98 from manufacturing and 32 from service sector).

\section{Measures}

HPMP Questionnaire: The questionnaire used in this study was adapted from Wiesner, McDonald, and Banham (2007). Wiesner has used this questionnaire in exploring HPMP in the Australian context. However,the reliability and content validity of the updated questionnaire were also addressed. The HPMP components such as recruitment; selection; training and development; performance appraisal; and employee involvement in decision making were used in the survey. The sustainability outcomes are measured in terms of financial sustainability outcomes and market-based sustainability outcomes. Four questions including annual revenue growth; return on sales; return on equity; liquidity soundness are used to measure financial sustainability outcomes while, three questions including customer satisfaction; quality of products and services and market share change measures marketbased sustainability outcomes. The content validity of the revised questionnaire was determined by interviewing and presenting the questionnaire to 10 SME owner-managers in different SMEs within Karachi, Pakistan. In addition, five managers from SMEDA (Small and Medium Enterprise Development Authority Pakistan) were invited to comment on the questionnaire. The purpose of these interviews was to determine which aspects of 'HPMP' in the questionnaire are of practical importance to the Pakistani context and suitable to Pakistani SMEs. This was followed by a pilot survey conducted in 20 different SMEs in Karachi, Pakistan. On the basis of the interview feedback and results from the pilot survey, the survey instrument was revised and presented to the selected sample. For construct validity, exploratory factor analysis was performed by using SPSS v. 19 principal components analysis (PCA) with Varimax rotation. The exploratory nature of the study and 
the need to develop formative composite measures of the variables under study justify the use of PCA. Under PCA, items are retained and used to form a composite factor if they have a minimum factor loading of .40 (Hair et al., 2006). A reliability analysis indicated a Cronbach Alpha Coefficients of between 0.62 and 0.80 for each section.

\section{Results}

\section{Exploratory Factor Analysis}

For the purpose of preparing the data for further analysis and hypotheses testing, Principal Components Analysis (PCA) was performed on HPMP variables. A Varimax rotation (orthogonal) was used since the factors extracted were not designed to correlate (Costello \& Osborne, 2005). The exploratory nature of the study and the need to develop composite measures of the variables under study, justify the use of PCA. Under PCA, items were retained and used to form a composite factor if they have a minimum factor loading of 0.40 (Hair et al., 2006). Based on the PCA results, Table 1 indicates that Bartlett's Test of Sphericity was significant for all components of HPMP and SME sustainability constructs. The Kaiser-Meyer-Olkin (KMO) values were all above 0.60 (Tabachnick \& Fidell, 2001). Based on the nature of practices utilised by SMEs, were named as e.g:Normative (most of firms employed these practices), Niche (practices were marginally used by respondent SMEs), Normative Formal (practices are formal in nature and most of firms were using these practices), Contemporary (practices tend to represent more recent approaches), and Participatory-Evaluative ( practices include participation of others in the selection process and they are evaluative in nature).

\section{The Relationship between HPMP and SME Sustainability Out- comes}

This section reports the results pertaining to H1 and H2. For analysing these hypotheses, Structural equation modelling (SEM) was used to examine the relationship between independent and dependent variables. Based on the data preparation and the results of exploratory factor analysis all latent construct variables were entered in Smart PLS 2. The following constructs (with their codes) were used in the structural and measurement model.

Recruitment (REC);Selection (SE); Training \& Development (T\&D); Performance appraisal (PA); Compensation (COM); Consultation (CONS); Financial Sustainability outcomes (FSUS); Market-based sustainability outcomes (MSUS); Normative (Recruitment) (RNOR); Internal sources (Recruitment) (RINT); Normative Formal (Selection) (SNOR); Participatory Evaluative (Selection) (SPART); Informal (Training \& Development) (TINF); Niche (Training \& Development) (TNIC); Organisational Development (Training \& Development) (TOD); Contemporary (Performance Appraisal) (PACON); Systemic (Performance Appraisal) (PASYS); Company-wide incentives (Compensation) (CCOMP); Specific incentives (Compensation (CSP); Operational (Consultation) (CONOP); Strategic (Operational) (CONST). 
Table 1

Exploratory Factor Analysis of HPMP and Sustainability outcomes

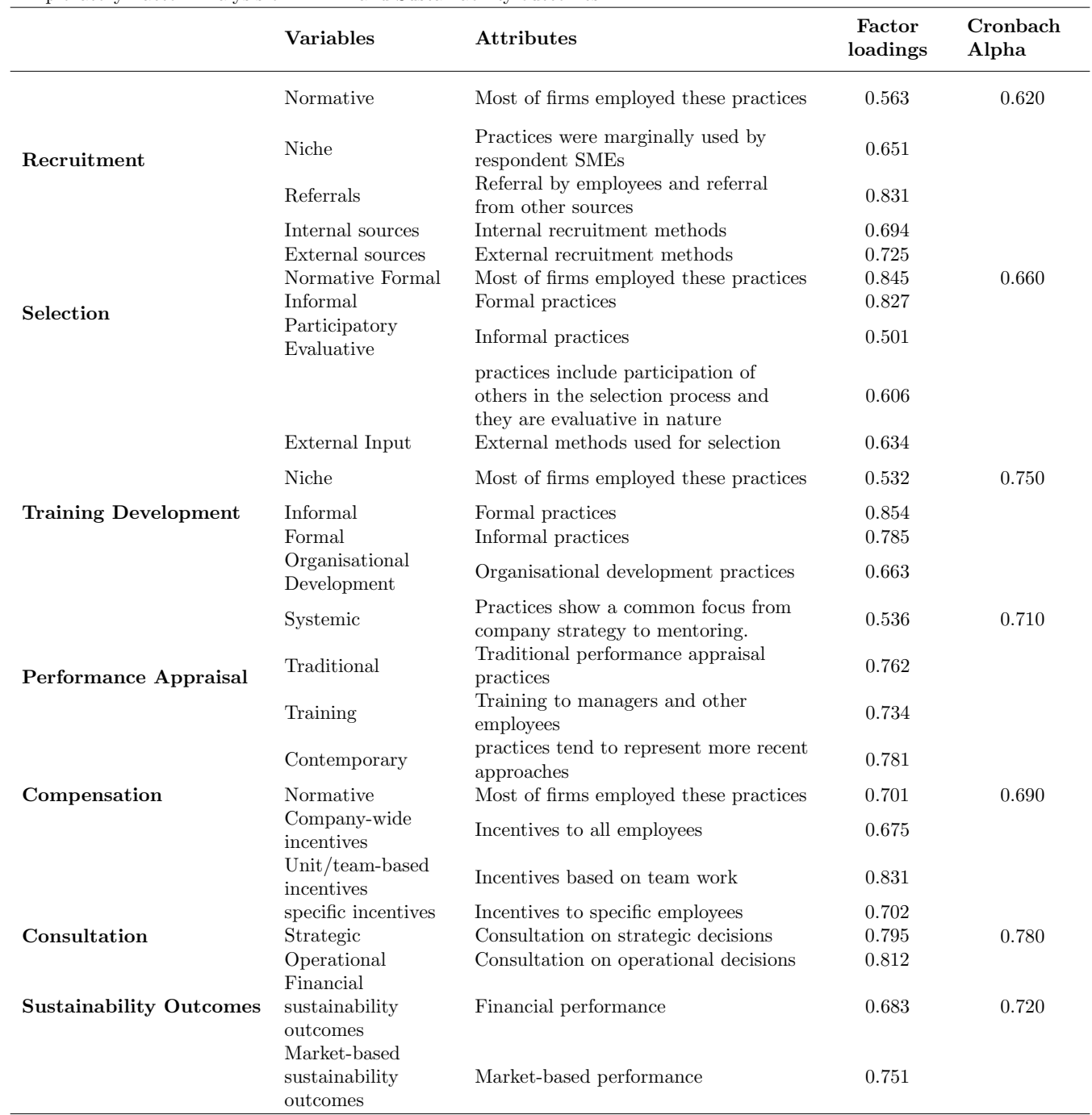

The PLS algorithm was used with the path weighting scheme and standard values in terms of iterations and abort criteria. For the purpose of using standardised model parameters, a Z-transformation was applied on the data set. (Chin, 2010) two phases approach was applied. The first phase was approached by analysing the reliability and validity of the measurement model while the second phase was undertaken by running the structural model with standardised path coefficients, $\mathrm{R}$ square values, and t-statistics. 
Table 2

Measurement Model: Composite Reliability, Average Variance Extracted (AVE)

\begin{tabular}{llll}
\hline Constructs & CR & AVE & $\sqrt{A V E}$ \\
\hline FSUS & 0.812 & 0.591 & 0.768 \\
CCOMP & 0.811 & 0.682 & 0.825 \\
COM & 0.753 & 0.435 & 0.659 \\
CONOP & 0.892 & 0.624 & 0.789 \\
CONS & 0.825 & 0.441 & 0.664 \\
CONST & 0.889 & 0.801 & 0.895 \\
CSP & 0.843 & 0.729 & 0.854 \\
MSUS & 0.858 & 0.669 & 0.818 \\
PA & 0.814 & 0.471 & 0.687 \\
PACON & 0.809 & 0.68 & 0.825 \\
PASYS & 0.855 & 0.663 & 0.814 \\
REC & 0.799 & 0.403 & 0.635 \\
RINT & 0.801 & 0.669 & 0.818 \\
RNOR & 0.813 & 0.522 & 0.723 \\
SEL & 0.815 & 0.477 & 0.690 \\
SNOR & 0.874 & 0.776 & 0.881 \\
SPART & 0.892 & 0.735 & 0.857 \\
T\&D & 0.914 & 0.474 & 0.689 \\
TINF & 0.93 & 0.816 & 0.903 \\
TNIC & 0.919 & 0.621 & 0.788 \\
TOD & 0.850 & 0.739 & 0.860 \\
\hline Source: Authors' Estimation & & & \\
*: The values of $\sqrt{A V E}$ show the correlation matrix for each pair of constructs, \\
the absolute value of their correlation is below the square root of AVE of each \\
construct which is a support for Discriminant validity (Fornell \& Larcker, 1981 ).
\end{tabular}

As discussed above, a measurement model is assessed by its reliability and validity. In order to address the reliability and validity of the measurement model (first phase), the above Table 2 is designed to show the Average Variance Extracted (AVE), the composite reliability (CR), construct correlation matrix, and the square root of AVE. The results of the $\mathrm{CR}$ values for most of the constructs are above 0.8 showing high internal consistency among the variables of each construct. Moreover, the outer model loadings are well above the accepted criteria of 0.7 indicating internal consistency of the measurement model.

The convergent validity $(\mathrm{CV})$ results presented in Table shows that the AVE values for most of the constructs are above 0.5 (with the exception of few constructs showing slightly below 0.5 ) indicating 50 percent or more variance of the indicators. The AVE and CR values indicate that each latent construct is well represented by its indicators. However, according to (Malhotra, 2008) the AVE is a more conservative measure than CR and for addressing $\mathrm{CV}$ a researcher may rely on $\mathrm{CR}$ value alone. For assessing the discriminant validity of the measurement model, the construct correlations are calculated and compared with square root of AVE. The results show that all constructs are highly related to their own measures than with other constructs (Chin, 2010). Moreover, Table is designed to present the outer model loadings and cross loadings of the constructs (Chin, 2010). The results indicate that each item relates to its own construct (loadings) and do not have stronger relationship with the indicators of other constructs (cross loadings). 
Table 3

Measurement Model: Standardised path coefficients, Mean, standard deviation, and standard error

\begin{tabular}{|c|c|c|c|c|c|}
\hline & $\begin{array}{c}\text { Standardised } \\
\text { Path } \\
\text { coefficient }\end{array}$ & Sample Mean & $\begin{array}{l}\text { Standard } \\
\text { Deviation }\end{array}$ & $\begin{array}{l}\text { Standard } \\
\text { Error }\end{array}$ & t-Statistics \\
\hline COM $\rightarrow$ FSUS & 0.060 & 0.060 & 0.060 & 0.060 & 1.070 \\
\hline $\mathrm{COM} \rightarrow \mathrm{CCOMP}$ & 0.790 & 0.790 & 0.030 & 0.030 & $25.640^{* * *}$ \\
\hline $\mathrm{COM} \rightarrow \mathrm{CSP}$ & 0.780 & 0.780 & 0.050 & 0.050 & $17.140^{* * *}$ \\
\hline COM $\rightarrow$ MSUS & 0.030 & 0.030 & 0.070 & 0.070 & 0.350 \\
\hline CONS $\rightarrow$ FSUS & 0.210 & 0.210 & 0.050 & 0.050 & $3.960 * * *$ \\
\hline CONS $\rightarrow$ CONOP & 0.980 & 0.980 & 0.010 & 0.010 & $67.120^{* * *}$ \\
\hline CONS $\rightarrow$ CONST & 0.250 & 0.250 & 0.120 & 0.120 & $2.040^{* *}$ \\
\hline CONS $\rightarrow$ MSUS & 0.250 & 0.250 & 0.050 & 0.050 & $4.710^{* * *}$ \\
\hline PA $\rightarrow$ FSUS & 0.020 & 0.020 & 0.080 & 0.080 & 0.270 \\
\hline PA $\rightarrow$ MSUS & 0.050 & 0.070 & 0.090 & 0.090 & 0.580 \\
\hline $\mathrm{PA} \rightarrow \mathrm{PACON}$ & 0.710 & 0.700 & 0.060 & 0.060 & $11.410^{* * *}$ \\
\hline PA $\rightarrow$ PASYS & 0.920 & 0.920 & 0.020 & 0.020 & $59.460^{*}$ \\
\hline REC $\rightarrow$ FSUS & 0.080 & 0.080 & 0.060 & 0.060 & 1.300 \\
\hline REC $\rightarrow$ MSUS & 0.020 & 0.030 & 0.070 & 0.070 & 0.340 \\
\hline REC $\rightarrow$ RINT & 0.680 & 0.680 & 0.050 & 0.050 & $14.760^{* * *}$ \\
\hline REC $\rightarrow$ RNOR & 0.930 & 0.930 & 0.010 & 0.010 & $97.980^{* * *}$ \\
\hline SEL $\rightarrow$ FSUS & 0.110 & 0.100 & 0.070 & 0.070 & 1.440 \\
\hline SEL $\rightarrow$ MSUS & 0.080 & 0.070 & 0.090 & 0.090 & 0.890 \\
\hline $\mathrm{SEL} \rightarrow$ SNOR & 0.620 & 0.610 & 0.070 & 0.070 & $8.300^{* * *}$ \\
\hline SEL $\rightarrow$ SPART & 0.900 & 0.900 & 0.020 & 0.020 & $53.880^{* * *}$ \\
\hline T\&D $\rightarrow$ FSUS & 0.310 & 0.310 & 0.060 & 0.060 & $4.770 * * *$ \\
\hline T\&D $\rightarrow$ MSUS & 0.260 & 0.260 & 0.090 & 0.090 & $3.030 * * *$ \\
\hline $\mathrm{T} \& \mathrm{D} \rightarrow \mathrm{TINF}$ & 0.720 & 0.730 & 0.030 & 0.030 & $28.000^{*}$ \\
\hline $\mathrm{T} \& \mathrm{D} \rightarrow \mathrm{TNIC}$ & 0.940 & 0.940 & 0.010 & 0.010 & $102.800^{*}$ \\
\hline T\&D $\rightarrow$ TOD & 0.640 & 0.650 & 0.060 & 0.060 & $10.200^{*}$ \\
\hline
\end{tabular}

\section{Model Evaluation: Structural Model Results}

Figure 1

Structural Model: Path coefficients, Significance level, and $\mathrm{R}$ square values

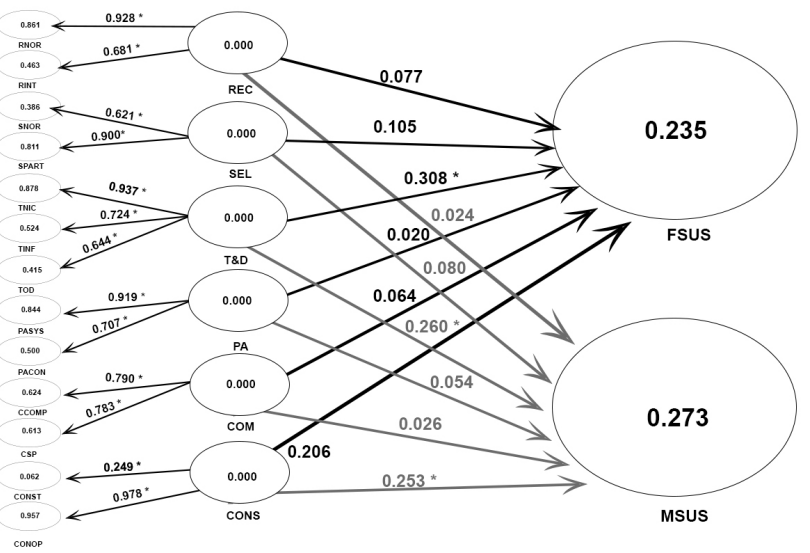


The structural model results represent the second phase of model evaluation (Chin, 2010). The R-square values (explaining variance in the model) for the endogenous constructs (Financial sustainability outcomes (FSUS); Market-based sustainability outcomes (MSUS)) are shown in Table.

Table 4

Measurement Model: Path Coefficients, Sample Mean, Standard Deviation, Standard Error, and T Statistics of First-Order Constructs and Financial Sustainability Outcomes construct

\begin{tabular}{|c|c|c|c|c|c|}
\hline & $\begin{array}{c}\text { Standardised } \\
\text { Path } \\
\text { coefficient } \\
\left(\gamma_{p}\right) \\
\end{array}$ & Sample Mean & $\begin{array}{l}\text { Standard } \\
\text { Deviation }\end{array}$ & $\begin{array}{l}\text { Standard } \\
\text { Error }\end{array}$ & t-statistics \\
\hline RINT $\rightarrow$ FSUS & 0.040 & 0.040 & 0.060 & 0.060 & 0.760 \\
\hline RNOR $\rightarrow$ FSUS & 0.090 & 0.090 & 0.060 & 0.060 & 1.4300 \\
\hline SNOR $\rightarrow$ FSUS & 0.100 & 0.090 & 0.050 & 0.050 & $1.820^{*}$ \\
\hline SPART $\rightarrow$ FSUS & 0.010 & 0.020 & 0.080 & 0.080 & 0.140 \\
\hline TINF $\rightarrow$ FSUS & 0.040 & 0.050 & 0.050 & 0.050 & 0.830 \\
\hline TNIC $\rightarrow$ FSUS & 0.100 & 0.110 & 0.090 & 0.090 & 1.220 \\
\hline TOD $\rightarrow$ FSUS & 0.220 & 0.220 & 0.060 & 0.060 & $3.960^{* * *}$ \\
\hline CSP $\rightarrow$ FSUS & 0.040 & 0.020 & 0.050 & 0.050 & 0.750 \\
\hline CCOMP $\rightarrow$ FSUS & 0.010 & 0.020 & 0.060 & 0.060 & 0.220 \\
\hline PACON $\rightarrow$ FSUS & 0.040 & 0.050 & 0.060 & 0.060 & 0.740 \\
\hline PASYS $\rightarrow$ FSUS & 0.090 & 0.100 & 0.090 & 0.090 & 1.040 \\
\hline CONOP $\rightarrow$ FSUS & 0.210 & 0.210 & 0.050 & 0.050 & $4.580^{* * *}$ \\
\hline CONST $\rightarrow$ FSUS & 0.170 & 0.170 & 0.050 & 0.050 & $3.400^{* * *}$ \\
\hline
\end{tabular}

The $\mathrm{R}^{2}$ value for FSUS indicates 0.235 variance in the model predicted by independent latent variables (Recruitment (RE), election (SE), Training \& Development (T\&D), Performance Appraisal (PA), Compensation (COM) and Consultation (CONS)). While the R2 value for MSUS indicate 0.273 variance in the model predicted by independent variables.

The significance of path coefficients $\gamma_{p}$ is tested by bootstrapping. A 1000 sample is taken for 331 cases. A t-statistics is calculated for each path coefficients among the latent constructs. All firs-order latent construct indicate positive significant path coefficients towards their respective second-order latent constructs at significance level $p<0.05$. While the path coefficients from second-order latent construct to endogenous dependent variables (FSUS; MSUS) indicate mixed results. The path coefficient for T\&D to FSUS and MSUS; and CONS to FSUS and MSUS indicate significant relationships at $p<0.05$ while all second-order latent variables present insignificant relationship with either FSUS or MSUS.

\section{Model Evaluation: First-order Constructs and Dependent Latent Variables}

The measurement and structural model was further evaluated by examining the relationship between first-order constructs (factors of High Performance Management Practices) and individual endogenous dependent variables (Financial sustainability outcomes (FSUS) and Market-based sustainability outcomes (MSUS)). Although such analysis is not part of hypothesis testing, however the analysis could help the researcher of this study to further investigate the effect of each first-order latent construct on FSUS and MSUS. 
Table 5

Measurement Model: Path Coefficients, Sample Mean, Standard Deviation, Standard Error, and t- Statistics of First-Order Constructs and Market-based Sustainability Outcomes construct

\begin{tabular}{|c|c|c|c|c|c|}
\hline & $\begin{array}{c}\text { Standardised } \\
\text { Path } \\
\text { coefficient }\end{array}$ & Sample Mean & $\begin{array}{l}\text { Standard } \\
\text { Deviation }\end{array}$ & $\begin{array}{c}\text { Standard } \\
\text { Error }\end{array}$ & t-statistics \\
\hline RINT $\rightarrow$ MSUS & 0.050 & 0.040 & 0.070 & 0.070 & 0.770 \\
\hline RNOR $\rightarrow$ MSUS & 0.100 & 0.100 & 0.060 & 0.060 & 1.600 \\
\hline SNOR $\rightarrow$ MSUS & 0.070 & 0.070 & 0.050 & 0.050 & 1.440 \\
\hline SPART $\rightarrow$ MSUS & 0.220 & 0.240 & 0.090 & 0.090 & $2.490^{* *}$ \\
\hline TINF $\rightarrow$ MSUS & 0.160 & 0.160 & 0.050 & 0.050 & $2.980^{* *}$ \\
\hline TNIC $\rightarrow$ MSUS & 0.120 & 0.120 & 0.090 & 0.090 & 1.270 \\
\hline TOD $\rightarrow$ MSUS & 0.040 & 0.050 & 0.060 & 0.060 & 0.570 \\
\hline PACON $\rightarrow$ MSUS & 0.030 & 0.030 & 0.070 & 0.070 & 0.460 \\
\hline PASYS $\rightarrow$ MSUS & 0.240 & 0.240 & 0.090 & 0.090 & $2.600 * *$ \\
\hline CCOMP $\rightarrow$ MSUS & 0.080 & 0.090 & 0.070 & 0.070 & 1.200 \\
\hline $\mathrm{CSP} \rightarrow \mathrm{MSUS}$ & 0.070 & 0.080 & 0.060 & 0.060 & 1.190 \\
\hline CONOP $\rightarrow$ MSUS & 0.210 & 0.210 & 0.050 & 0.050 & $4.540 * * *$ \\
\hline CONST $\rightarrow$ MSUS & 0.200 & 0.200 & 0.050 & 0.050 & $4.390^{* * *}$ \\
\hline
\end{tabular}

The below table present the results for the relationship between first-order construct and FSUS. The results indicate that SNOR (Normative Selection practices), TOD (Training organisation development practices), CONOP (Consultation operating practices) and CONST(Consultation Strategic practices) are positive significant predictors of FSUS.

The relationship between first-order construct and MSUS are presented in Table 5. The results indicate that RNOR (Normative Recruitment practices); SPART(Selection Participatory evaluative practices); TINF (Training Informal practices); PASYS(Performance Appraisal Systemic); CONOP(Consultation operating practices); and CONST(Consultation Strategic practices) are positive significant predictors of MSUS.

\section{Discussion}

This study examines the relationship between HPMPs and SME sustainability outcomes (Financial and Market-based sustainability outcomes) in Pakistan. Of the twenty?three HPMP components eight are positively associated with Financial Sustainability outcomes and nine are positively associated with Market-based sustainability outcomes.

Normative recruitment, Formal Normative Selection and Normative Compensation, which represent generally mainstream practices used by Pakistani SME aside from the most popular informal practices, show a positive association with both Financial and Marketbased sustainability outcomes. These findings indicate that such HPMP practices are positively affecting annual revenue growth; return on sales, return on equity, liquidity soundness ,customer satisfaction, quality of products and services and market share change. These components are less informal than some other more popular informal components such as recruitment through informal referrals, informal selection and informal training and development which are favoured by Pakistani SMEs, they do contain some degree of formality. One could argue that this finding is generally good news for the Pakistani context since these practices do feature relatively strongly in the respondent organisations. 
Other HPMP components which comprise more formal practices such as: Other formal components such as Niche Recruitment, External Recruitment Sources, Participatoryevaluative selection, external input in selection, Niche T\&D, Formal T\&D, Systemic PA and Traditional PA, Company-wide compensation, Team based compensation and Specific compensation featured very weak in the respondent organisations. One explanation that has been put forward is the possible lack of knowledge about the value these practices could add to the management of their employees. However, these HPMP components did not significantly relate to either the Financial or Market-based sustainability in Pakistani SMEs.

Similarly, no significant associations were found between the aforementioned informal components and Financial Sustainability outcomes and Market-based Sustainability Outcomes. One could argue that this represents a bleak picture for Pakistani SMEs in view of their over-reliance upon these types of informal HPMP practices.

Broadly, there are two orientations to the literature concerning HPMP practices relevant to the context of SMEs which align with the formal and informal orientations of management more commonly found in the SME literature. The first, concerning formality, draws upon normative business management approaches as HPMP provides tactical-level practices to operationalise strategic planning. The majority of the published research indicates the positive role of formal HPMP as a source of competitive advantage and that certain HPMP practices improve organisational performance and firm resilience (Arthur, 1994; Huselid, 1995; Ichniowski et al., 1997; Tsai, 2006) Therefore, a lack of formal HPMP approaches could be interpreted as a negative within the Pakistani SME context.

However, another perspective has also been argued in the literature. De Kok and Uhlaner (2001) and Wiesner et al. (2007) argue that small firms tend to adopt more informal HPMP in comparison to large firms. This notion has widely been acknowledged in research studies indicating the positive relationship between firm size and the adoption of HPMP (De Kok \& Uhlaner, 2001; Delery \& Doty, 1996; Lawler et al., 1995; Marlo, 2000; Wiesner \& McDonald, 2001; Wiesner et al., 2007). However, informality in small firms reflect their needs and types of management and thus are more dependent on informal interactions which integrate their norms and direct behaviours. Moreover, Bacon, Ackers, Storey, and Coates (1996) argue that the communication in small organisations is more direct and informal and employees tend to have more flexibility. They also argue that small firms have a horizontal hierarchy and the contribution of each employee to organisation performance is more obvious. In addition, they assert that due to high insecurity, small firms are more responsive to changes in customer demands and markets. Similarly, small firms tend to use more informal approaches to change in comparison to formal bureaucratic approaches employed by large firms. As a result, it is much easier to bring about change in small firms than in large organisations (Bacon et al., 1996). Misztal (2002) argue that informality may be driver of effective interactions and communication in a small, familyowned and single owner/manager SMEs as is mainly the case in our study

In view of this second argument, the lack of relationship between the aforementioned informal HPMP components and both financial and market-based sustainability, does not necessarily predict an overall negative picture for Pakistani SMEs.

Two other practices that showed a positive impact upon both Financial and Market- 
based sustainability are the training component, Organisational Development practices (management and development training, introduced new formal training, increased training programs, introduced new career paths) and the performance appraisal component Contemporary Performance Appraisal (management by objective, assessment centre, balance score card approach). Performance Appraisal Training also positively correlates with Financial Sustainability and Systemic Performance Appraisal positively correlates with Market-based Sustainability, both of which these performance appraisal practices were employed to a minor extent in respondent organisations. Other authors found similar results (Ichniowski et al., 1997; Katou \& Budhwar, 2007; Lange, Ottens, \& Taylor, 2000; Singh, 2004; Michie \& Sheehan, 2003; Van de Wiele, 2010).

Even though these components are employed to a minor extent in the respondent firms, the link between these HPMP components and the sustainability of SMEs demonstrates the value and importance of these HPMP components in achieving sustainability. In view of the fact that Pakistani SMEs are in a growth phase, there seems to a need for Pakistani SMEs to realise the prominence and importance of the role of a skilled and a more career oriented labour force could play in achieving sustainability. Moreover, Hussain et al. (2015) noted that small firms are facing the issues of productivity and quality particularly at the operational level. Afraz et al. (2014) also identified constraints and barriers to growth of small firms in Pakistan. Thus, there is a need for raising the awareness of Pakistani SMEs of the important role performance appraisal could play in improving the performance of SMEs (Ichniowski et al., 1997; Lange et al., 2000; Pansiri \& Temtime, 2008) especially in view of the mentioned growth phase in which Pakistani SMEs find themselves. The adoption of formal practices such as a 360 degree appraisal method, management by ojectives, assessment centres, provision of training to managers who appraise performance, and provision of training to employees who recieve performance appraisal could enhance the performance profile of SMEs (Bartel, 2004).

A positive link was found between the degree of consulting employees in decision-making (in relation to both strategic and operational issues) and both Financial and Market-based sustainbaility. Our finding is supported by studies such as (Gollan, 2005; Katou \& Budhwar, 2007; Shih et al., 2006; Zwick, 2004). However, our finding is quite disturbing in view of the low levels of consulting with employees on both strategic and operational issues. Regarding the link between consultation and firm performance, prior research studies have indicated a positive relationship between employee consultation/involvement and firm performance (Gollan, 2005; Katou \& Budhwar, 2007; Shih et al., 2006; Zwick, 2004). O'Regan, Sims, and Ghobadian (2005) argue that decentralised structures tend to bring about employee motivation and creativity. Their study found that leading firms tend to empower their staff particularly on important issues such as staff development and disciplinary matters. Kato and Morishima (2002) argue that employee participation or involvement both at the top level and at the grass root level, may enhance the productivity of a firm. Their results are in line with Zwick (2004) who indicates that team work; autonomous work groups and low levels of hierarchical arrangements provide organisations with a productivity advantage. Through formal or informal consultation, managers and employees expect to achieve organisational objectives such as effectiveness, productivity, product quality and organisational change (Sagie \& Koslowsky, 2000). Gollan (2005) argue that the sustainabil- 
ity of HPMP can only be achieved by recognising the needs of employees and implementing sustainable policies and practices through employee involvement and participation. Wagar (1998) argues that firms with open communication styles and employee participation in decision making tend to adopt more HPMPs.

However in view of the results in this study that indicate minor levels of consultation of employees on both strategic and operational issues, it is clear that Pakistani SMEs are not taking advantage of the benefits of consultation. Regarding the two main sectors (manufacturing and services-based firms) in Pakistan economy, our findings indicate a greater use of consultation practices in service-based firms than in manufacturing firms. The results are in line with the study of Rana, Khan, Asad, and Mian (2007) of 650 manufacturing firms which found that about eighty-two percent of SME owners are the operating head and make the major strategic decisions in their firms. Given the positive link between participative management practices and firm performance (as discussed above), service-based firms have shown rapid growth in the Pakistan economy. The contribution of the services sector to economic growth has increased to 53.3 percent in 2010-11 which is the highest contribution in the last two decades. The sector achieved a growth rate of 4.1 percent and has a share of 90 percent of the overall GDP growth rate (Economic Survey, 2015).

\section{Conclusion}

The two main hypotheses that inform research objective were partially supported. There is positive significant relationship between HPMP and sustainability outcomes in Pakistani SMEs. This study addressed the research gaps reported in the literature . For instance, this study contributes to the limited research conducted in the area of high performance management practices (HPMP) in SMEs (Kroon et al., 2013). This study adds value to the literature of HPMP by analysing the human resource aspect of SMEs within a developing country which is under researched. Most of the prior studies in this area are conducted in the developed world (De Kok et al., 2006; Huselid, 1995; Kehoe \& Wright, 2013; Kroon et al., 2013; Rowden, 2002; Shih et al., 2006; Way, 2002; Wiesner et al., 2007).

This study provides support for the configurational perspective which hypothesise that certain HPMP work together to enhance firm performance (Delery \& Doty, 1996). SMEs could not possibly be capable of either considering or practically using HR practices as understood in a unidimensional manner-in other words SMEs simply do not have the resources to use the wide range of HR practices employed in large organisations. Instead, best-practice is far more likely to emerge in context and in limited clusters of HR practices.The configurational perspective focuses on internally consistent configurations of HR practices, or employment systems that identify the relationship between HR practices and strategic configurations (Arthur, 1994; Delery \& Doty, 1996; Fernando et al., 2005; Huselid \& Becker, 1996; Ichniowski et al., 1997).

For SMEs, due to their smaller size and lack of resources, limited HR practices could be expected. For instance, in relation to selection practices, some SMEs might use more normative formal and informal practices along with one on one interviews or unstructured 
interviews while others focus on participatory-evaluative practices such as work samples or assessment centres, and while a minority of SMEs might continue utilising external input such as consultants or other senior employees/managers in the final selection process. Thus, based on the configurational approach, different clusters of HR practices are equally effective which might contradict the idea of a single set of 'best practices'. The configurational approach is therefore in favour of using different clusters of HR practices within each HR domain/index.

The survey findings supported the configurational perspective since the impact of every separate HPMP component on sustainability has been analysed, but the combined impact of these components on financial and market-based sustainability has also been explored.

Like any other research, this study is not without its limitations. First, the data has been obtained from a single person in the form of owners/managers who rated their HPMP in their organisations (Gerhart, Wright, Manhan, \& Snell, 2000). However, collecting data from owners/mangers, managing directors or the chief executive officer (CEO) as the selfreporting person is a common approach since CEOs are well informed about all strategic and operational activities within the organisation (Frost, Birkinshaw, \& Ensign, 2002) Within the SME context it is specifically appropriate since the SMEs owner/manager is the key person who run most of the affairs of business and take most of the strategic decisions (Rana et al., 2007). Nevertheless, in order to enhance the internal validity of the research, an extension of this study to collect data from employees within the organisations may be beneficial (Shih et al., 2006).

This study has been conducted in the Pakistani context and the data for this research study was collected from SMEs in service-based and manufacturing firms in a single city (Karachi) within Pakistan. Thus, caution should be applied for interpreting the generalisability of results. However, Karachi is the biggest industrial city of Pakistan. It contributes 25 percent to national GDP (KMC, 2012). It also shares 65 percent in national revenue such as federal and provincial taxes, customs and surcharges (KMC, 2012).

This research study was conducted within a cultural context which is under researched, underdeveloped and also quite different to other Western cultures and nations. In order to enhance the external validity of this study, the results of this study could be compared to similar studies in other cultures and countries. The external validity issue has been addressed to a certain extent by adapting the survey questionnaire from another study conducted in another country (Australia).

The survey in this study was conducted at a single point in time. Longitudinal data will also further clarify the causal relationships between HPMP and sustainability outcomes (Tsai, 2006).

This study provides one of the most thorough analyses of HPMP (individual variables, components and sub-components) compared to other existing studies which measure their HPMP constructs with only a few individual variables. This may appear to be overly complex and unnecessary. However, after conducting a research review of the definitions and measurement of HPMP as part of the literature review, it became evident that all six components (recruitment, selection, training and development, performance appraisal, compensation and consultation) are critical to the in-depth analysis of HPMP.

Finally, because this study focuses on exploring (HPMP) in SMEs with 20-250 em- 
ployees, firms with employee sizes below 20 and above 250 fall outside the scope of this study. 


\section{References}

Afraz, N., Hussain, S. T., \& Khan, U. (2014). Barriers to the Growth of Small Firms in Pakistan: A Qualitative Assessment of Selected Light Engineering Industries. The Lahore Journal of Economics, 19, 135-147.

Arthur, J. B. (1994). Effects of human resource systems on manufacturing performance and turnover. Academy of Management Journal, 37(3), 670-687.

Bacon, N., Ackers, P., Storey, J., \& Coates, D. (1996). It's a small world: managing human resources in small businesses. International Journal of Human Resource Management, 7(1), 82-100.

Bae, K.-S., Chuma, H., Kato, T., Kim, D.-B., \& Ohashi, I. (2011). High performance work practices and employee voice: A comparison of Japanese and Korean workers. Industrial Relations: A Journal of Economy and Society, 50(1), 1-29.

Baird, L., \& Meshoulam, I. (1988). Managing two fits of strategic human resource management. Academy of Management Review, 13(1), 116-128.

Barney, J. (1991). Firm resources and sustained competitive advantage. Journal of Management, 17(1), 99-120.

Barney, J. (1995). Looking inside for competitive advantage. The Academy of Management Executive, 9(4), 49-61.

Bartel, A. P. (2004). Human resource management and organizational performance: Evidence from retail banking. Industrial \& Labor Relations Review, 57(2), 181-203.

Becker, B. E., Huselid, M. A., Becker, B., \& Huselid, M. A. (1998). High performance work systems and firm performance: A synthesis of research and managerial implications. In Research in Personnel and Human Resource Management (pp. 53-102).

Beltrán-Martín, I., Roca-Puig, V., Escrig-Tena, A., \& Bou-Llusar, J. C. (2008). Human resource flexibility as a mediating variable between high performance work systems and performance. Journal of Management, 34(5), 1009-1044.

Bryson, A., Forth, J., \& Kirby, S. (2005). High-involvement management practices, trade union representation and workplace performance in Britain. Scottish Journal of Political Economy, 52(3), 451-491.

Chin, W. W. (2010). How to write up and report PLS analyses. In Handbook of Partial Least Squares (pp. 655-690). Springer, Germany.

Chow, I. H., Huang, J.-C., \& Liu, S. (2008). Strategic HRM in China: Configurations and competitive advantage. Human Resource Management, 47(4), 687-706.

Combs, J., Liu, Y., Hall, A., \& Ketchen, D. (2006). How much do high-performance work practices matter? A meta-analysis of their effects on organizational performance. Personnel Psychology, 59(3), 501-528.

Costello, A., \& Osborne, J. (2005). Best practices in exploratory factor analysis: Four. Practical Assessment, Research \& Evaluation, 10(7), 9-21.

Datta, D. K., Guthrie, J. P., \& Wright, P. M. (2005). Human resource management and labor productivity: does industry matter? Academy of Management Journal, 48(1), $135-145$.

De Kok, J., Den Hartog, D., et al. (2006). High performance work systems, performance and innovativeness in small firms. EIM Scales Paper. Retrieved from https:// 
core.ac.uk/download/files/153/7074589.pdf

De Kok, J., \& Uhlaner, L. M. (2001). Organization context and human resource management in the small firm. Small Business Economics, 17(4), 273-291.

Delery, J. E., \& Doty, D. H. (1996). Modes of theorizing in strategic human resource management: Tests of universalistic, contingency, and configurational performance predictions. Academy of Management Journal, 39(4), 802-835.

Drummond, I., \& Stone, I. (2007). Exploring the potential of high performance work systems in SMEs. Employee Relations, 29(2), 192-207.

Economic Survey. (2015). Pakistan Economic Survey 2014-15. Overview of the Economy. Retrieved from http://www.finance.gov.pk/survey_1011.html

Ekwoaba, J. O., Ikeije, U. U., \& Ufoma, N. (2015). High-performance work systems and organizational performance: The mediating role fo internal social structure. Global Journal of Human Resource Management, 3(2), 22-33.

Evans, W. R., \& Davis, W. D. (2005). High-performance work systems and organizational performance: The mediating role of internal social structure. Journal of Management, $31(5), 758-775$.

Ferligoj, A., Prašnikar, J., \& Jordan, V. (1997). Competitive advantage and human resource management in SMEs in a transitional economy. Small Business Economics, $9(6), 503-514$.

Fernando, M.-A., Pedro, M. R.-F., \& Gonzalo, S.-G. (2005). Strategic human resource management: integrating the universalistic, contingent, configurational and contextual perspectives. The International Journal of Human Resource Management, 16(5), 633-659.

Fleetwood, S., \& Hesketh, A. (2006). HRM-performance research: Under-theorized and lacking explanatory power. The International Journal of Human Resource Management, $17(12), 1977-1993$.

Fornell, C., \& Larcker, D. F. (1981). Evaluating structural equation models with unobservable variables and measurement error. Journal of Marketing Research, 18(1), $39-50$.

Frost, T. S., Birkinshaw, J. M., \& Ensign, P. C. (2002). Centers of excellence in multinational corporations. Strategic Management Journal, 23(11), 997-1018.

Gerhart, B., Wright, P. M., Manhan, G. C., \& Snell, S. A. (2000). Measurement error in research on human resources and firm performance: how much error is there and how does it influence effect size estimates? Personnel Psychology, 53(4), 803-834.

Gollan, P. J. (2005). High involvement management and human resource sustainability: The challenges and opportunities. Asia Pacific Journal of Human Resources, 43(1), $18-33$.

Gould-Williams, J. (2003). The importance of HR practices and workplace trust in achieving superior performance: A study of public-sector organizations. International Journal of Human Resource Management, 14(1), 28-54.

Guest, D. E., Michie, J., Conway, N., \& Sheehan, M. (2003). Human resource management and corporate performance in the UK. British Journal of Industrial Relations, 41(2), 291-314.

Guthrie, J. P., Spell, C. S., \& Nyamori, R. O. (2002). Correlates and consequences of high 
involvement work practices: the role of competitive strategy. International Journal of Human Resource Management, 13(1), 183-197.

Hair, J. F., Black, W. C., Babin, B. J., Anderson, R. E., Tatham, R. L., et al. (2006). Multivariate Data Analysis (Vol. 6). Pearson Prentice Hall Upper Saddle River, NJ.

Heneman, R. L., Tansky, J. W., \& Camp, S. M. (2000). Human resource management practices in small and medium-sized enterprises: Unanswered questions and future research perspectives. Entrepreneurship: Theory and Practice, 25(1), 11-11.

Hofstede, G. (2010). National cultural dimensions. Retrieved from http://www.geert -hof stede.com/index.shtml

Huselid, M. A. (1995). The impact of human resource management practices on turnover, productivity, and corporate financial performance. Academy of Management journal, $38(3), 635-672$.

Huselid, M. A., \& Becker, B. E. (1996). Methodological issues in cross-sectional and panel estimates of the human resource-firm performance link. Industrial Relations: A Journal of Economy and Society, 35(3), 400-422.

Hussain, A., Ahmad, Q. W., Haq, I. U., Nazir, A., Imran, S., \& Islam, B. U. (2015). Improving Productivity and Quality in SMEs of Pakistan: A case study. Technical Journal, 20(2), 103-114.

Ichniowski, C., Shaw, K., \& Prennushi, G. (1997). The effects of human resource management practices on productivity: A study of steel finishing lines. The American Economic Review, 87(3), 291-313.

Irfan, S. M., Kee, D. M. H., Qureshi, R. W., \& Hussain, R. (2014). Measuring performance of SMEs in Pakistan using PLS-SEM: Evaluating MBNQA criteria as TQM framework. Science International, 26, 1707-1718.

Kato, T., \& Morishima, M. (2002). The productivity effects of participatory employment practices: Evidence from new Japanese panel data. Industrial Relations: A Journal of Economy and Society, 41(4), 487-520.

Katou, A. A., \& Budhwar, P. S. (2007). The effect of human resource management policies on organizational performance in Greek manufacturing firms. Thunderbird International Business Review, 49(1), 1-35.

Kehoe, R. R., \& Wright, P. M. (2013). The impact of high-performance human resource practices on employees' attitudes and behaviors. Journal of Management, 39(2), 366-391.

Khilji, S. E. (2004). Whither tradition? Evidence of generational differences in HR satisfaction from Pakistan. International Journal of Cross Cultural Management, $4(2), 141-156$.

KMC. (2012). City district government Karachi. Retrieved from http://221.132.118 .186/cdgk/Home/AboutKarachi/Economy/tabid/271/Default.aspx

Koch, M. J., \& McGrath, R. G. (1996). Improving labor productivity: Human resource management policies do matter. Strategic Management Journal, 17(5), 335-354.

Kroon, B., Van De Voorde, K., \& Timmers, J. (2013). High performance work practices in small firms: A resource-poverty and strategic decision-making perspective. Small Business Economics, 41(1), 71-91. 
Lange, T., Ottens, M., \& Taylor, A. (2000). SMEs and barriers to skills development: a Scottish perspective. Journal of European Industrial Training, 24(1), 5-11.

Lawler, E., Mohrman, S., \& Ledford, G. (1995). Creating high performance organizations: Survey of practices and results of employee involvement and TQM in fortune 1000 companies. John \& Sons Incorporated.

Malhotra, N. K. (2008). Marketing research: An Applied Orientation (5th ed.). Pearson Education, India.

Marlo, S. (2000). Investigating the use of emergent strategic human resource management activity in the small firm. Journal of Small Business and Enterprise Development, $7(2), 135-148$.

Michie, J., \& Sheehan, M. (2003). Labour market deregulation,'flexibility'and innovation. Cambridge Journal of Economics, 27(1), 123-143.

Miles, R. E., Snow, C. C., Meyer, A. D., \& Coleman, H. J. (1978). Organizational strategy, structure, and process. Academy of Management Review, 3(3), 546-562.

Misztal, B. (2002). Informality: Social theory and contemporary practice. Routledge, New York.

Murphy, K. S., DiPietro, R. B., \& Murrmann, S. (2007). A proposed research agenda for the refinement of the high performance work system construct in the US restaurant industry. International Journal of Hospitality $\&$ Tourism Administration, 8(4), 99116.

O’Regan, N., Sims, M., \& Ghobadian, A. (2005). High performance: ownership and decision-making in SMEs. Management Decision, 43(3), 382-396.

Pansiri, J., \& Temtime, Z. T. (2008). Assessing managerial skills in smes for capacity building. Journal of Management Development, 27(2), 251-260.

Pfeffer, J. (1998). Seven practices of successful organizations. California Management Review, 40(2), 96-124.

Rana, A., Khan, J., Asad, U., \& Mian, S. A. (2007). The SME pulse: An exploratory study of the performance of SMEs in Pakistan and the characteristics of successful firms. Small and Medium Enterprise Center, Lahore University of Management Sciences, 3(1), 47-53.

Richard, O. C., \& Johnson, N. B. (2001). Strategic human resource management effectiveness and firm performance. International Journal of Human Resource Management, 12(2), 299-310.

Rose, R. C., Kumar, N., \& Yen, L. L. (2006). Entrepreneurs success factors and escalation of small and medium-sized enterprises in Malaysia. Journal of Social Sciences, 2(3), $74-80$.

Rowden, R. W. (2002). High performance and human resource characteristics of successful small manufacturing and processing companies. Leadership $\mathscr{E}$ Organization Development Journal, 23(2), 79-83.

Sagie, A., \& Koslowsky, M. (2000). Employee participation-what does it mean.

Schuler, R. S., \& MacMillan, I. C. (1984). Gaining competitive advantage through human resource management practices. Human Resource Management, 23(3), 241-255.

Shih, H.-A., Chiang, Y.-H., \& Hsu, C.-C. (2006). Can high performance work systems really lead to better performance? International Journal of Manpower, 27(8), 741-763. 
Singh, K. (2004). Impact of HR practices on perceived firm performance in India. Asia Pacific Journal of Human Resources, 42(3), 301-317.

Tabachnick, B. G., \& Fidell, L. S. (2001). Using Multivariate Statistics. Allyn and Bacon Boston, New York.

Takeuchi, N. (2009). How Japanese manufacturing firms align their human resource policies with business strategies: testing a contingency performance prediction in a Japanese context. The International Journal of Human Resource Management, 20(1), 34-56.

Tsai, C.-J. (2006). High performance work systems and organizational performance: an empirical study of Taiwan's semiconductor design firms. The International Journal of Human Resource Management, 17(9), 1512-1530.

Van de Wiele, P. (2010). The impact of training participation and training costs on firm productivity in Belgium. The International Journal of Human Resource Management, $21(4), 582-599$.

Wagar, T. H. (1998). Determinants of human resource management practices in small firms: Some evidence from Atlantic Canada. Journal of Small Business Management, $36(2), 13-23$.

Way, S. A. (2002). High performance work systems and intermediate indicators of firm performance within the US small business sector. Journal of Management, 28(6), $765-785$.

Wernerfelt, B. (1984). A resource-based view of the firm. Strategic Management Journal, $5(2), 171-180$.

Whitener, E. M. (2001). Do "high commitment" human resource practices affect employee commitment? A cross-level analysis using hierarchical linear modeling. Journal of Management, 27(5), 515-535.

Wiesner, R., \& McDonald, J. (2001). Bleak house or bright prospect? Human resource management in Australian SMEs. Asia Pacific Journal of Human Resources, 39(2), $31-53$.

Wiesner, R., McDonald, J., \& Banham, H. C. (2007). Australian small and medium sized enterprises (SMEs): A study of high performance management practices. Journal of Management \& Organization, 13(3), 227-248.

Wood, S., \& De Menezes, L. (1998). High commitment management in the UK: Evidence from the workplace industrial relations survey, and employers' manpower and skills practices survey. Human Relations, 51 (4), 485-515.

Wright, P. M., Dunford, B. B., \& Snell, S. A. (2001). Human resources and the resource based view of the firm. Journal of Management, 27(6), 701-721.

Wright, P. M., Gardner, T. M., Moynihan, L. M., \& Allen, M. R. (2005). The relationship between HR practices and firm performance: Examining causal order. Personnel Psychology, 58(2), 409-446.

Wright, P. M., \& McMahan, G. C. (1992). Theoretical perspectives for strategic human resource management. Journal of Management, 18(2), 295-320.

Wright, P. M., McMahan, G. C., \& McWilliams, A. (1994). Human resources and sustained competitive advantage: a resource-based perspective. International Journal of Human Resource Management, 5(2), 301-326.

Yasmin, R. (2008). A Study on the Effects of Strategic HRM Systems on Performance: 
The Case of Pakistani Manufacturing Companies. Japanese Journal of Administrative Science, 21(1), 47-60.

Zhang, Y.-C., \& Li, S.-L. (2009). High performance work practices and firm performance: evidence from the pharmaceutical industry in China. The International Journal of Human Resource Management, 20(11), 2331-2348.

Zheng, C., O’Neill, G., \& Morrison, M. (2009). Enhancing chinese sme performance through innovative hr practices. Personnel Review, 38(2), 175-194.

Zwick, T. (2004). Employee participation and productivity. Labour Economics, 11(6), $715-740$. 